\title{
Founding the International Society of Complementary Medicine Research
}

\author{
Marja J. Verhoef*
}

On November 22, 2003, delegates of the 10th Annual Symposium on Complementary Healthcare packed into the main lecture hall of the Royal College of Physicians in London to take a momentous step in the history of complementary medicine research. Sara Warber (USA) and Edzard Ernst (UK) chaired the meeting and began by introducing the Working Group for the International Society of Complementary Medicine Research. In addition to Warber and Ernst, the Working Group included Alan Bensoussan (Australia), Brian Berman (USA), Vinjar Fønnebø (Norway), Harley Goldberg (USA), Katherine Gundling (USA), George Lewith (UK), Kate Thomas (UK), Marja Verhoef (Canada) and Hitoshi Yamashita (Japan). During the past few months, this group had communicated via e-mail to prepare the following purpose and goals for the proposed Society.

\section{Purpose}

A multidisciplinary scientific organization to foster the development and dissemination of new knowledge regarding whole person healing and whole systems healthcare research, including traditional, holistic, alternative, complementary and integrative forms of medicine.

\section{Goals}

1) Enhance communication and build collegial relations among researchers and practitioners on a worldwide basis

2) Provide a voice in understanding the scope of the field and promoting excellence in research

3) Provide and promote forums for the presentation of peer-reviewed original research

4) Collaborate with regional societies and professional organizations to further mutual goals

5) Form relationships with peer-reviewed journals in the field

A show of hands in support of the International Society was nearly unanimous amongst the delegates. During the symposium, the candidates who were nominated for office were announced and provided the opportunity to speak about their vision for the Society and their qualifications. Following a brief question period about the structure and mandate of the new organization, delegates submitted their ballots electing Marja Verhoef, $\mathrm{PhD}$, (Canada) as President; George Lewith, MD, PhD, (UK) as President-Elect; Sara Warber, MD, (USA) as Secretary; and Suzanna Zick, ND, MPH, (USA) as Treasurer. The officers have been assigned the responsibility of establishing the Society's infrastructure and developing relationships with other groups in the field. Delegates had the opportunity to become a Founding Member of the Society, or become a part of the advisory board that is currently being established.

In a welcoming letter to the Founding Members, new president Marja Verhoef charted her vision. 'As efficient communication is vital to launching and sustaining a new society such as ours, our first efforts will be focused on establishing a Website to share information about meetings, reports, opportunities and other issues that the membership decides are important. We will also begin making an effort to link and collaborate with existing CAM research groups and networks to enhance integration of our Society with the $C A M$ research community.' Dr Verhoef went on to emphasize the importance of membership feedback for guiding the officers and the Board as they begin their work to provide a forum for sharing research. This may take the form of satellite meetings alongside established meetings or perhaps co-sponsorship of a meeting.

Membership is open to any individual whose interests are consistent with the purpose and goals of the organization. For application materials, please contact the ISCMR Secretary, Sara L. Warber, MD, 715 E. Huron, Ann Arbor, MI 48158, USA. Tel: 1-734-998-7715, Fax: 1-734-998-7720. E-mail: camrc@umich.edu

*President, ISCMR, E-mail: mverhoef@ucalgary.ca 


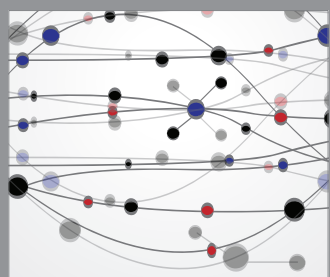

The Scientific World Journal
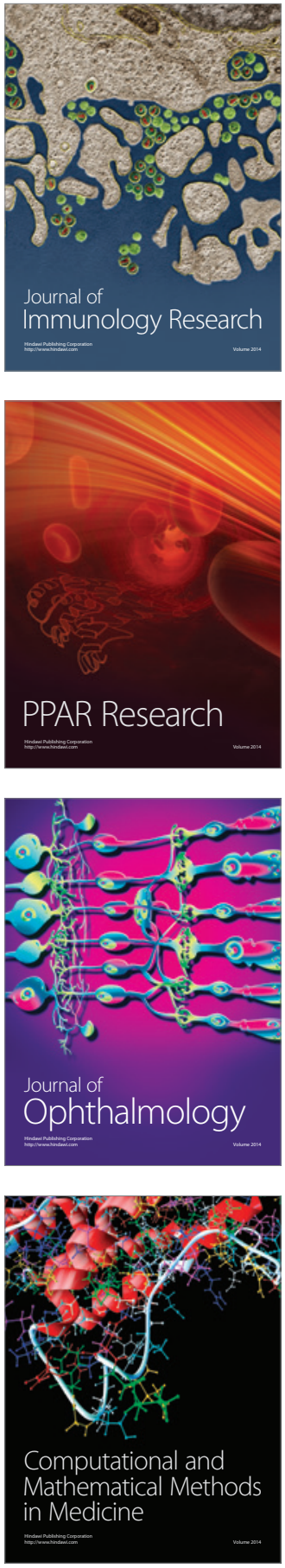

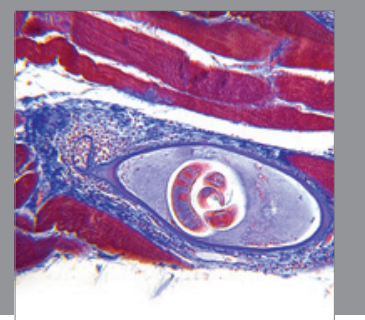

Gastroenterology

Research and Practice
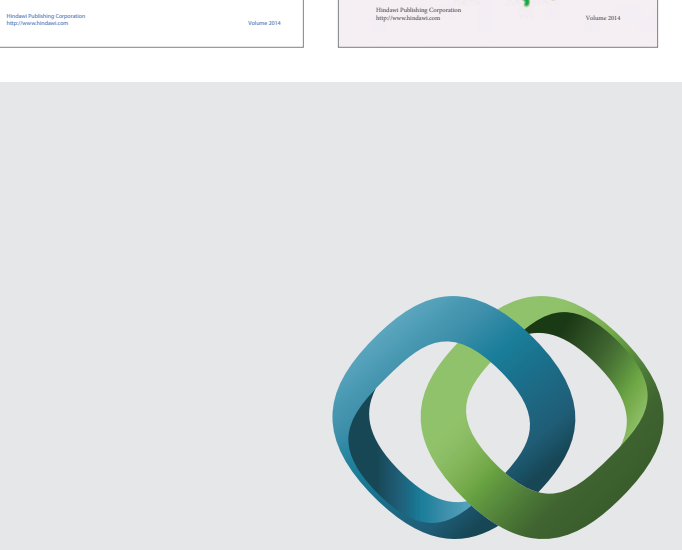

\section{Hindawi}

Submit your manuscripts at

http://www.hindawi.com
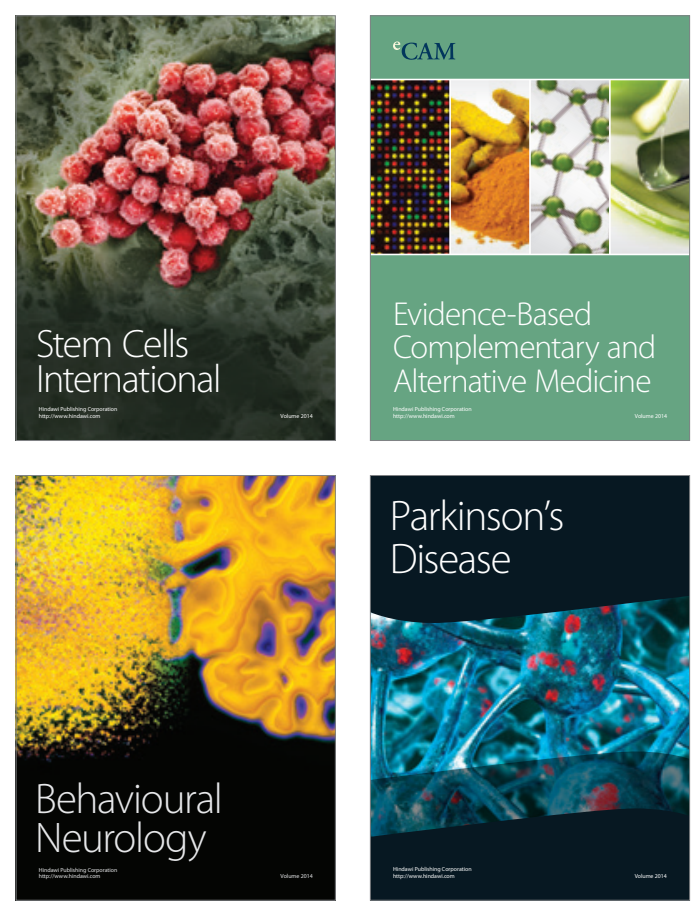

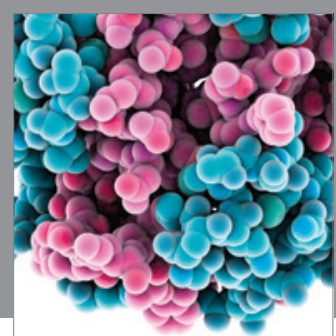

Journal of
Diabetes Research

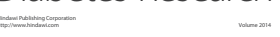

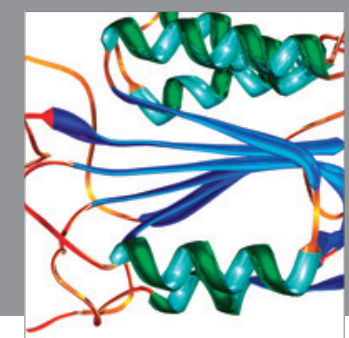

Disease Markers
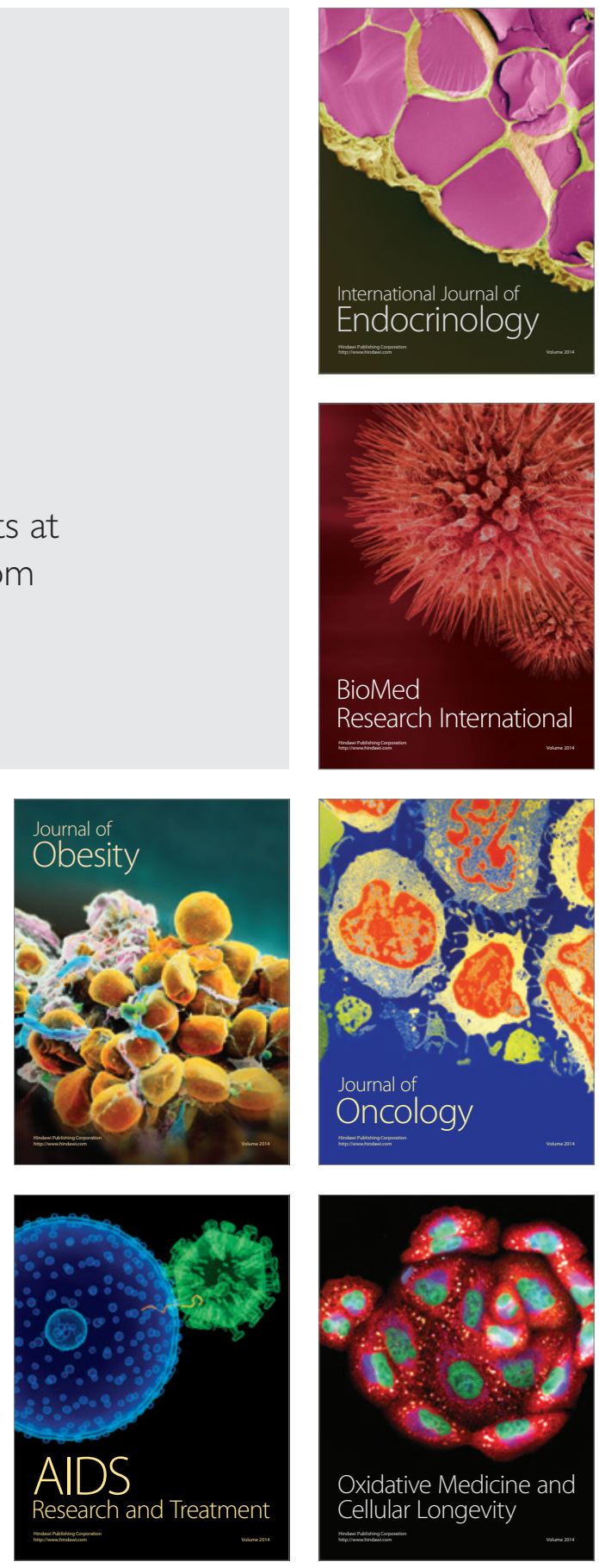